\title{
A Nuclepore Filter Bag for Preparation of Small Biological Specimens for Scanning Electron Microscopy
}

\author{
YASUE NAKAMURA \\ Laboratory of Oceanography, Faculty of Agriculture, \\ Tohoku University, Sendai 981, Japan
}

(Received March 14, 1991-Accepted August 21, 1991)

\begin{abstract}
A method for the preparation of minute, delicate and dilute suspended organisms for scanning electron microscopy (SEM) by using of Nuclepore filter bags (NFB) is described. NFBs are easily made by welding with a heat sealer and are inert with solvents used in the preparation of specimens for SEM. The use of NFB avoids the risk of unintentional air-drying, physical damage, contamination, and loss of specimens during preparation. Specimens prepared by NFB show fine details of three-dimensional surface structure.
\end{abstract}

Key words : Nuclepore filter bag (NFB), scanning electron microscopy (SEM), specimen preparation, small delicate organisms.

\section{Introduction}

Scanning electron microscopy (SEM) has been employed for morphological and taxonomical studies of marine planktonic microalgae. However, it is not always easy to prepare microalgal specimens for SEM. Conventional and widely employed methods to concentrate and handle suspended specimens are centrifugation and filtration ${ }^{1,3,8,12,13)}$. However, during these procedures some specimens form aggregates, are damaged or lost, so that large volume water samples and/or high densities of microalgae are necessary. To overcome these problems, investigators have devised a variety of preparation techniques for suspended specimens.

Marchant ${ }^{8)}$, Scott et al. ${ }^{20)}$, Klainer et al..$^{4)}$, Postek et al. ${ }^{16)}$, Enlander et al. ${ }^{2)}$, Rostgaad and Christensen ${ }^{18)}$, Newell and Roath ${ }^{11)}$ and Tayler ${ }^{21)}$ have designed their own containers to handle concentrated specimens by centrifugation in order to avoid possible losses during the successive steps of critical point drying. Other workers including
Paerl' ${ }^{13)}$, Paerl and Shimp ${ }^{14)}$, Wetzel et al. ${ }^{25)}$, Melkonian ${ }^{9)}$, and Platt et al. ${ }^{15)}$ have filtered microalgae to collect specimens from the dilute suspensions found in natural seawater. Loeblich and Sherley ${ }^{6}$ have used specimens placed on Formvarcoated copper grids for examination under both SEM and transmission electron microscopy. Mazia et al. ${ }^{7)}$, Sanders et al. ${ }^{19)}$, Tsutsui et al. ${ }^{23,24)}$, Tawara et al. ${ }^{22)}$, Nakayama and Honma ${ }^{10)}$ and Kumon et al..$^{5)}$ have used polycationic substances to collect algal cells from suspension without physical damage to the algae. Nevertheless, there seems still be some problems in preparation of microalgae for SEM.

We report here a useful design of a semipermeable filter bag to process dilute suspensions of small delicate specimens for SEM. Our main purposes are; 1) to treat small amounts of cultured samples, 2) to process specimens from dilute suspensions without loss and damage due to centrifugation and filtration under suction, and 3) to avoid contamination during handling. The filter bags should;1) be easy to construct, 2) 
allow exchange of fluids of various solvents, 3) allow processing of many samples at one time, 4) obviate unintentional air-drying during the procedure, and 5) allow observation of fine structure under SEM

\section{Materials and Methods}

\section{Selection of filter materials}

To construct bags bearing the characteristics mentioned above, filters must be permeable, flexible, elastic, smooth and resistant to the organic solvents used to prepare specimens for SEM. Among the filters tested, Millipore filters (HAWP \& HATF, Millipore Corp.), Gelman Metricel filter (Gelman Metricel Corp.), Whatman GF/C filters (Whatman International Ltd.) and Flotronic filter (Selas Flotronics Ltd.) do not fulfill the requirements. Dialysis membrane tubing (Nakarai Chem. Ltd., M.W. cutoff 3500) and Nuclepore filters (Nuclepore Corp.) are adequate for the present purpose (Table 1, Fig. 2). As shown in Table 1 and Fig. 2, Nuclepore filters and dialysis membrane tubing (DT) are well suited for making filter bags. The bags can hold specimens throughout all the steps from initial fixation to drying, during which most of the specimens inside adhere to the filter membrane. There was no significant difference in the morphology of the critical-point- dried specimens prepared with NFB and DT. Smooth surface of both Nuclepore filters and the dialysis membranes provide a suitable background when viewed under SEM. With NFB and DT, fixation and subsequent processing of several bags could be carried out using the same vials containing fixative and dehydrating solutions. It is possible to directly mount organisms adhering to a piece of the membrane on specimen stubs.

\section{Microalgae}

Natural algal populations were collected from Onagawa Bay, Japan, several times between 1979 and 1984. Seawater samples were collected from the surface to $30 \mathrm{~m}$ depth with a Van Dorn bottle or a pump and the seawater was stored in polyethylene bottles. Subsamples $(1-5 \mathrm{ml})$ were immediately processed for SEM upon return to the laboratory. Subsamples were fixed by the addition of glutaraldehyde to achieve a final concentration of $2.5 \%$ in $0.025 \mathrm{M}$ sodium cacodylate buffer with seawater either before or after transferring the subsamples to the bags.

In addition to natural samples, batch cultures of the diatom Chaetoceros gracile were also processed for SEM using the NFB or DT technique. The diatom was grown in Matsudaira medium (Table 2) at $20^{\circ} \mathrm{C}$ on $14: 10 \mathrm{LD}$ cycle under fluorescent light or under room temperature and room

Table 1. Porosity, resistance to chemicals, surface texture and flexibility of the filters tested.

\begin{tabular}{|c|c|c|c|c|c|c|c|}
\hline \multirow{2}{*}{ Filters } & \multirow{2}{*}{ Porosity } & \multirow{2}{*}{ Surface } & \multirow{2}{*}{ Flexibility } & \multicolumn{4}{|c|}{ Chemical Resistance } \\
\hline & & & & Glutaraldehyde & Amylacetate & Carbondioxide & Ethanol \\
\hline Millipore & & & & & & & \\
\hline HAWP & $\mathbf{R}$ & NR & NR & NR. & NR & $\mathbf{R}$ & $\mathbf{L}$ \\
\hline HATF & $\mathbf{R}$ & NR & $\mathrm{R}$ & $\mathrm{R}$ & $\mathrm{R}$ & $\mathbf{R}$ & $\mathrm{R}$ \\
\hline Gelman & $\mathbf{R}$ & NR & NR & NR & NR & $\mathbf{R}$ & $\mathrm{L}$ \\
\hline Whatman & & & & & & & \\
\hline $\mathrm{GF} / \mathrm{C}$ & $\mathrm{R}$ & NR & NR & $\mathbf{R}$ & $\mathbf{R}$ & $\mathrm{R}$ & $\mathrm{R}$ \\
\hline Flotronics & $\mathbf{R}$ & NR & $\mathrm{R}$ & $\mathrm{R}$ & $\mathbf{R}$ & $\mathrm{R}$ & $\mathbf{R}$ \\
\hline Nuclepore & $\mathrm{R}$ & $\mathbf{R}$ & $\mathrm{R}$ & $\mathrm{R}$ & $\mathbf{R}$ & $\mathbf{R}$ & $\mathbf{R}$ \\
\hline Dialysis & $\mathbf{R}$ & $\mathbf{R}$ & $\mathrm{R}$ & $\mathrm{R}$ & NR & $\mathrm{R}$ & $\mathbf{R}$ \\
\hline
\end{tabular}

$\mathrm{R}=$ Recommended $; \mathrm{NR}=$ Not recommended $; \mathrm{L}=$ Limited application 
Table 2. Composition of stock solutions for Matsudaira medium ${ }^{\text {a) }}$ used for algal culture.

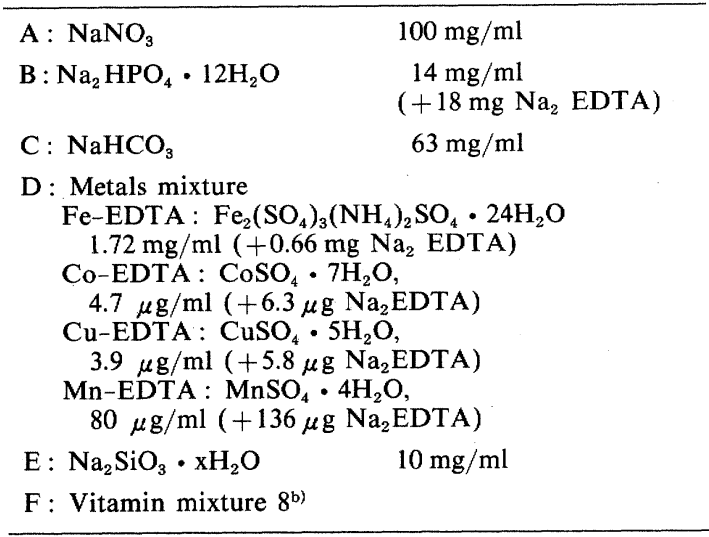

a) Stock solutions A-F were sterilized separately by autoclaving or filtration and then $1 \mathrm{ml}$ of solutions $\mathrm{A}, \mathrm{B}, \mathrm{D}, \mathrm{E}$ and $\mathrm{F}$ and $2 \mathrm{ml}$ of solution $\mathrm{C}$ were added to $1000 \mathrm{ml}$ of autoclaved Millipore HA filtered seawater.

b) Provasoli et $a l^{17}$.

light.

Preparation of specimens in Nuclepore filter bags

Figure 1 shows the preparation procedure with Nuclepore filter bags (NFB). An NFB was made of a half or a quarter of a $25 \mathrm{~mm}$ Nuclepore filter which was simply folded in half and welded with heat sealer (Polysealer PS210, Fuji MFG Co.) to form an open bag. A proper quantity of fixed or non-fixed samples was poured into the NFB with a Pasteur pipette and the seawater was blotted with a tissue paper (put on the outside of the NFB). Then the enclosed specimens were sealed into the NFB with the Polysealer, and then the specimens are washed and dehydrated by transferring the bag through vials containing buffer and a graded ethanol series. After dehydration, NFBs were transferred to a wire basket and placed in the critical point drying apparatus with liquid $\mathrm{CO}_{2}$.

$A$ piece of NFB on which dried specimens were present was mounted on a SEM stub with double stick tape with the inside of the NFB facing up. Specimens were coated by vacuum evaporation
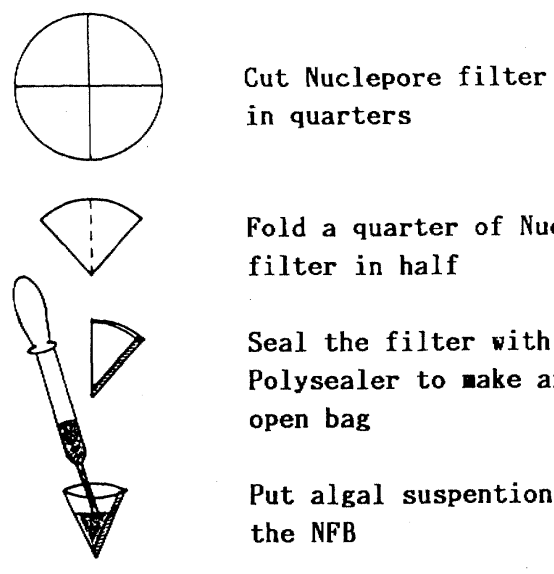

Fold a quarter of Nuclepore filter in half

Seal the filter with

Polysealer to make an open bag

Put algal suspention into the NFB

Close the NFB with

Polysealer

Rinse, fix and dehydrate in a vial

\section{Critical point drying in a basket}

Fig. 1. Sample preparation by the use of Nuclepore filter bags.

with gold and then observed under a Hitachi S700 scanning electron microscope at accelerating voltage of $15 \mathrm{kV}$. A few of the large-sized specimens were observed to detach from the filter during mounting coating procedures. However, the amount of specimens lost is very small in comparison with the lost of specimens with conventional methods.

\section{Preparation in dialysis tubing}

The dialysis tubing (DT) was wetted with sterile distilled water, and one end of DT was tied with a thread. Sample water was put into the DT and then the other end tied. Then the DT was handled in a similar way to the NFB described above.

Other preparation

To compare the results obtained by NFB and 
DT methods with those by conventional methods, preparations were also made using filtration, centrifugation and the polycationic substance layer method. In the filtration method, aliquots of fixed samples were filtrated under low vacuum pressure (below $100 \mathrm{mmHg}$ ) through a $0.2 \mu \mathrm{m}$ Nuclepore filter of $4 \mathrm{~mm}$ in diameter and desalted (three times) with particle-free distilled water. After air drying in a desiccator, the filters were mounted onto SEM stubs with double stick tape and then coated by vacuum evaporation with gold. In the polycationic substance layer method, samples were prepared according to the procedures described by Tsutsui et $a l^{23)}$. Specimens were also concentrated, washed and dehydrated using the centrifugation methods described by Osumi ${ }^{12)}$.

\section{Results and discussion}

Scanning electron micrographs of the specimens prepared in NFB are shown in Figs. 3-8 and those in DT are shown in Figs. 9, 10. Both yielded good preservation of the surface texture and gross morphological features of the specimens. However, it was difficult to make small bags of DT, and the dialysis membrane was damaged by the electron beam at accelerating voltages above $15 \mathrm{kV}$. This damage prevents detailed observations on the specimens, for the specimens can move on the damaged membrane during the observations.

This was not the case for Nuclepore filters, they were not damaged at high accelerating voltages. We conclude that NFB is a most appropriate tool for preparation of the SEM specimens from dilute suspensions of delicate organisms. Many variations of the bag illustrated in Fig. 1 are possible, because filters of many different sizes, porosities and shapes are available. This means that a wide variety of biological specimens, ranging from bacteria to larger unicellular algae and protozoa can be handled in NFBs.

Although most specimens adhere onto the inner surface of the filter bag, specimens sometimes form aggregates and some of the large specimens detach from the filter during coating by vacuum evaporation and mounting. In such case, the standard mounting methods must be also employed.

We compared the results obtained by NFB and DT methods with those obtained by conventional methods such as centrifugation, filtration and polycationic methods (Table 3). In the conventional methods, various degrees of contamination occurred, and aggregation of the specimens was also occasionally observed (Table 3 ). Physical damage and loss of the specimens seemed to be the most severe problems, so that large volume water samples and/or water samples densely populated by algae are necessary with conventional methods

Table 3. Comparison of various preparation methods of microalgal specimens for a scanning electron microscopy.

\begin{tabular}{|c|c|c|c|c|c|c|c|}
\hline Methods & NFB & DT & Centrifuge & Filtration & Polycation & Grid* & Container* \\
\hline Concentration system & $\mathrm{E}$ & $\mathrm{E}$ & $\mathrm{C}$ & $\mathrm{S}$ & $\mathrm{C}$ & $\mathrm{C}$ & $\mathrm{C}$ \\
\hline $\begin{array}{l}\text { Possibility of } \\
\text { contamination }\end{array}$ & A & A & $\mathrm{U}$ & $\mathrm{U}$ & $\mathrm{U}$ & $\mathrm{U}$ & $\mathbf{P}$ \\
\hline Physical damage & $\mathbf{P}$ & $\mathbf{P}$ & $\mathrm{U} \sim \mathrm{P}$ & $\mathrm{U}$ & $\mathrm{U} \sim \mathrm{P}$ & $\mathrm{U}$ & $\mathrm{P} \sim \mathrm{U}$ \\
\hline Risk of loss & A & A & $\mathrm{U}$ & $P \sim U$ & $\mathrm{U} \sim \mathrm{P}$ & $P \sim U$ & $P \sim U$ \\
\hline Risk of air-drying & A & A & $\mathrm{P} \sim \mathrm{U}$ & $\mathrm{U}$ & $\mathrm{U} \sim \mathrm{A}$ & $\mathrm{U} \sim \mathrm{A}$ & $A \sim U$ \\
\hline $\begin{array}{l}\text { Treatable numbers at } \\
\text { once }\end{array}$ & M & $\mathrm{F}$ & 1 & $1 \sim \mathrm{F}$ & 1 & 1 & $1 \sim F$ \\
\hline
\end{tabular}

$\mathrm{A}=$ avoidable $; \mathrm{C}=$ centrifugation $; \mathrm{E}=$ exudation $; \mathrm{F}=$ few $; \mathrm{M}=$ many $; \mathrm{P}=$ possible ;

$\mathrm{S}=$ suction ; $\mathrm{U}=$ unavoidable

* Although these two methods were not tested in the present study, the characteristics listed could be easily supposed from the references. 

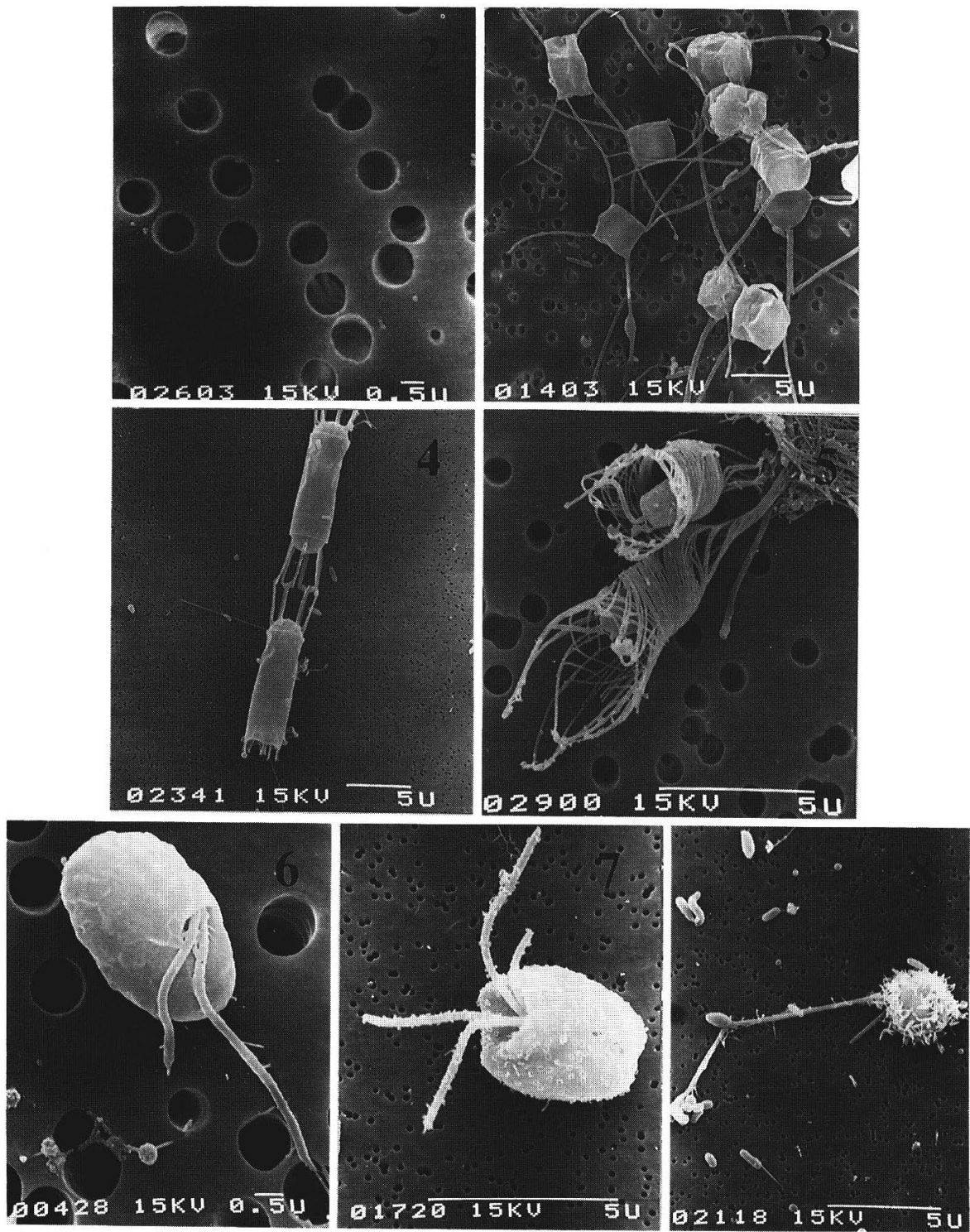

Fig. 2. The photograph shows that porosity, chemical resistance to solvents, surface texture and flexibility of the Nuclepore filters tested. This shows also that the NFB avoided contamination from external solution during handling.

Fig. 3-8. The specimens prepared by the NFB. The specimens were fixed with $2.5 \%$ glutaraldehyde in $0.025 \mathrm{M}$ sodium cacodylate buffer with seawater. Fig. 3.- Chaetoceros gracile cultured in Matsudaira medium (Table 2). Fig. 4.-Skeletonema costatum ; Fig. 5.-Acanthoeca spectabilis ; Fig. 6.Rhodomonas sp.; Fig. 7.-Pyramimonas sp.; Fig. 8.-a Chrysophycean nanoflagellate. The last five specimens occurred in enrichment cultures $(0-70 \mathrm{mg}-\mathrm{N} / 1)$ of natural seawater collected from Onagawa Bay. 


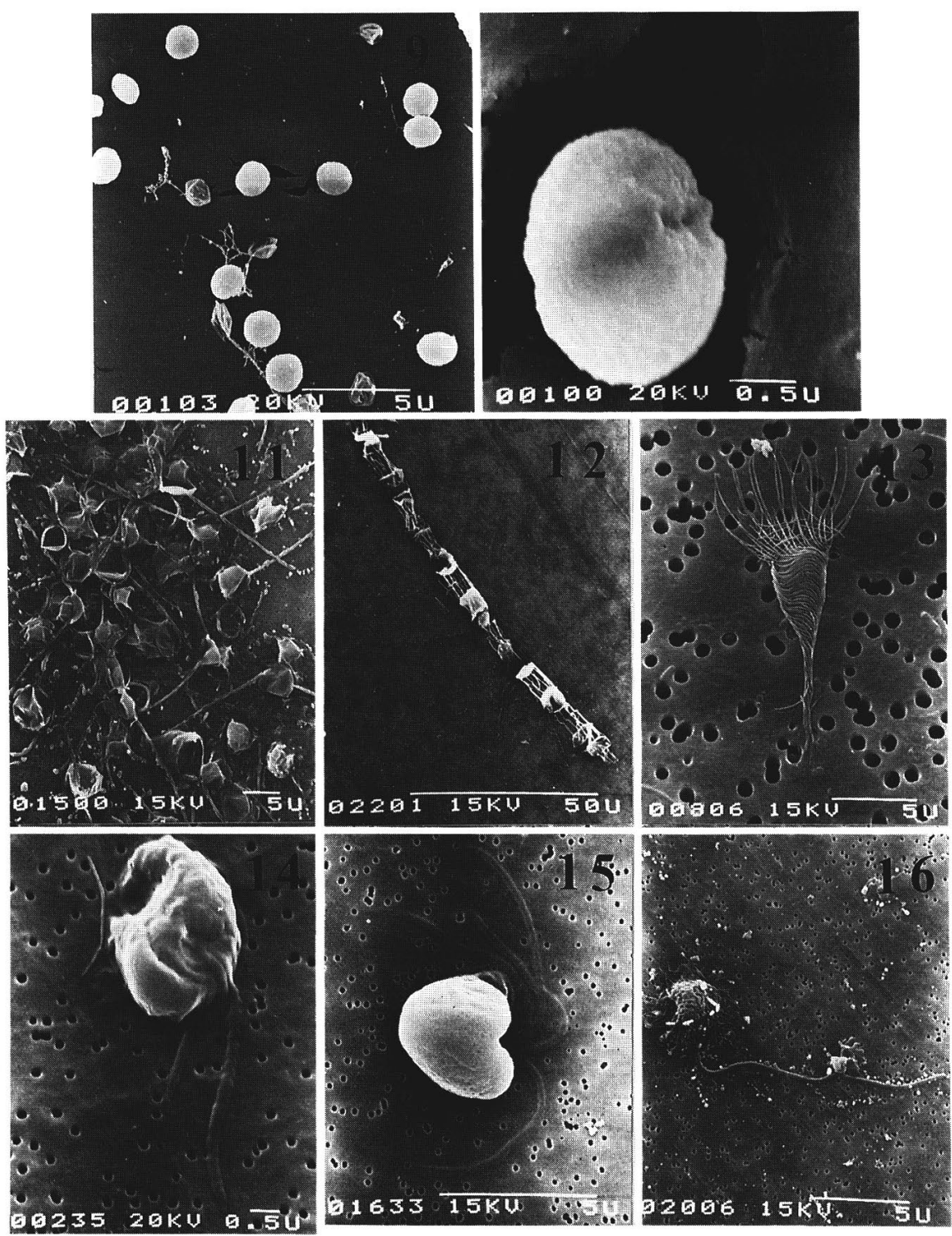

Fig. 9-10. Chlorella sp. prepared by the dialysis tube (DT). The dialysis membrane was damaged by the electron beam.

Fig. 11-16. The specimens prepared by the filtration method. These species are the same as Fig. 3-8.

Fig. 11.-Chaetoceros gracile cultured in Matsudaira medium.

Fig. 12.-Skeletonema costatum ; Fig. 13.-Acanthoeca spectabilis ; Fig. 14.-Rhodomonas sp.; Fig. 15.Pyramimonas sp.; Fig. 16.-a Chrysophycean nanoflagellate

(Table 3). As seen in Figs. 11-16, small-sized specimens are often irregularly damaged and flattened and these cannot be properly examined. Large-sized and armored cells such as diatoms withstood the filtration methods best. The specimens which can be prepared by the polycationic method are limited to negatively charged cells.

Based on these results, several distinct advan- 
tages of the NFB method over DT method as well as conventional methods are;

1) Sample size both in total cell number and cell density of microalgae can be reduced.

2) Nuclepore filters are resistant to solvents used in the preparation and to the electron beam.

3) NFB can be made easily and at low cost.

4) Use of NFB can eliminate contamination, loss and damage due to excessive handling which is necessary in centrifugation and filtration methods.

5) The NFB allows solvents to be exchanged rapidly because of its high permeability and this reduces the amount of solvents needed and handling time as well.

6) Many samples can be handled at the same time.

7) Risk of unintentional air-drying during the preparation is avoided.

On the other hand, this method has the following disadvantages;

1) Use of NFB is not able to prevent breakage of very delicate organisms by fixatives. Organic slime released from broken cells can sometimes destroy the remaining cells. This also occurs with the conventional methods.

2) Cells in NFB do not always distribute evenly over the inner surface of the bag. Therefore, a quantitative analysis of cell number by this method is difficult. To overcome these shortages, we need to explore the case of new fixatives and preparation of quantitative bags.

\section{Acknowledgements}

I would like to thank Dr. A. Taniguchi for valuable suggestions and Mr. T. Sato for technical assistance during this study, and Dr. Diane K. Stoecker at the University of Maryland for critical review of the MS and correction of the English.

\section{References}

1) Amako, K. 1982. Scanning electron micros- copy: An application to bacteriology. in "Electron Microscopy in Microbiology", Vol. 1, eds. by K. Amako and M. Koike. Gakkai Shuppan Senta, Tokyo, 1982, pp. 24-36 (in Japanese).

2) Enlander, D., T. Scott, and R.A. Tobey 1974. Observations of the surface of synchronized Chinese hamster ovary cells in suspension culture. II TRI/Scanning Electron Microscopy. II T Res Inst., Chicago, pp. 573-580.

3) Hayat, M.A. (ed.) 1978. Introduction to Biological Scanning Electron Microscopy. University Park Press, Baltimore, pp. 131-166.

4) Klainer, A.S., S. Jernigan, and P. Allender, 1974. Evaluation and comparison of techniques for examination of bacteria by scanning electron microscopy. II TRI/Scanning Electron Microscopy, II T Res Inst., Chicago, pp. 313-318.

5) Kumon, H., K. Ohno, Y. Matsumura, H. Ohmori, and T. Tanaka 1983. A new conductive substrate for preparing cells in suspension or scanning electron microscopy. J. Electron Microsc., 32, 20-26.

6) Loeblich, A.R. and J.L. Sherley, 1979. Observations on the theca of the motile phase of freeliving and symbiotic isolates of Zooxanthella microadriatica (Freudenthal) comv. nov. J. Mar. Biol. Assn. U.K., 59, 195-205.

7) Mazia, D., G. Schatten, and W. Sale 1975. Adhesion of cells to surfaces coated with polylysine. J. Cell Biol., 66, 198-200.

8) Marchant, H.J. 1973. Processing small delicate biological specimens for scanning electron microscopy. J. Microscopy, 97, 369-371.

9) Melkonian, M. 1981. The flagellar apparatus of the scaly green flagellate Pyramimonas obovata: Absolute configuration. Protoplasma, 108, 341-355.

10) Nakayama, Y. and T. Honma 1980. Scanning electron microscopic observation of non-E rosettes (lymphocytes adhering to less than tree RRBC) in guinea pigs. J. Electron Microsc., 29, 363-368.

11) Newell, D.G. and S. Roath 1975. A container for processing small volumes of cell suspension for critical point drying. J. Microscopy, 104, 321-323.

12) Osumi, M. 1982. Scanning electron microscopy : An application to mycology. in "Electron Microscopy in Microbiology", Vol. 1, eds. by K. Amako and M. Koike. Gakkai Shuppan Senta, Tokyo, 1982, pp. 3-21 (in Japanese).

13) Paerl, H.W. 1973. Detritus in Lake Tahoe: Structural modification by attached microflora. Science, 180, 496-498. 
14) Paerl, H.W. and L. Shimp 1973. Preparation of filtered plankton and detritus for study with scanning electron microscopy. Limnol. Oceanogr., 18, 802-805.

15) Platt, T., D.V. Subba Rao, and B. Irwin 1983. Photosynthesis of picoplankton in the oligotrophic ocean. Nature, 301, 702-704.

16) Postek, M.T., W.L. Kirk, and E.R. Cox 1974. A container for the processing of delicate organisms for scanning or transmission electron microscopy. Trans. Amer. Micros. Soc., 93, 265-267.

17) Provasoli, L., J.J.A. McLaughlin, and M.R. Droop 1957. The development of artificial media for marine algae. Arch. Microbiol., 25, 392-428.

18) Rostgaad, J. and P. Christensen 1975. A multipurpose specimen carrier for handling small biological objects through critical point drying. J. Microscopy, 105, 107-113.

19) Sanders, S.K., E.L. Alezander, and R.C. Braylan 1975. A high-yield technique for preparing cells fixed in suspension for scanning electron microscopy. J. Cell Biol, 67, 476-480.

20) Scott, J.R., E.L. Thurston, and T.R. Mckee 1973. A fine sieve processing container for use in critical point drying. J. Microscopy, 99,
359-360.

21) Tayler, P.G. 1975. A container for handling small specimens during preparation and examination in the scanning electron microscope (SEM). J. Microscopy, 105, 335-338.

22) Tawara, J., F. Uno, H. Kumon, K. Tsutsui, and N. Hayashi 1976. Scanning electron microscopic observation of hemagglutination reaction with influenza virus. J. Electron Microsc., 25, 37-38.

23) Tsutsui, K., H. Kumon, H. Ichikawa, and J. Tawara 1976. Preparative method for suspended biological materials for SEM by using of polycationic substance layer. J. Electron Microsc., 25, 163-168.

24) Tsutsui, K., H. Kumon, H. Ichikawa, and J. Tawara 1977. Preparative method for suspended biological materials for Scanning Electron Microscope. SEITAI NO KAGAKU, 28, 302-308 (in Japanese).

25) Wetzel, B., G.B. Cannon, E.L. Alexander, B.W. Erickson Jr., and E.W. Westbrook 1974. A critical approach to the scanning electron microscopy of cells in suspension. II TRI/ Scanning Electron Microscopy, II T Res Inst., Chicago, pp. 581-588. 